\title{
Bariatric Surgery In A Patient With Melanocortin 4 Receptor Mutation \\ Hanaa Elkhenini ${ }^{1,2}$, John P. New ${ }^{1,2}$ \& Akheel A. Syed ${ }^{1,2}$
}

1Obesity Medicine \& Endocrinology, Salford Royal NHS Foundation Trust \& University Teaching Hospital, Salford

${ }^{2}$ The University of Manchester, Manchester

\section{Introduction}

Whilst bariatric surgery is the most effective therapy for idiopathic morbid obesity in adults, little is known about its effectiveness in patients with monogenic obesity syndromes. We report 5-year outcome of gastric bypass surgery in a young man with severe super-obesity associated with melanocortin 4 receptor (MC4R) mutation.

\section{Case report}

A 22-year-old male with a weight of $221.6 \mathrm{~kg}$ and body mass index $76.7 \mathrm{~kg} / \mathrm{m}^{2}$ was referred to our centre for bariatric surgery. Previous attempts at lifestyle measures, dieting and treatment with Orlistat had been ineffective.

\section{Clinical background}

Hyperphagia, early weight gain, increased linear growth. Height $170.5 \mathrm{~cm}$, weight $177 \mathrm{~kg}$, body mass index 60.9 $\mathrm{kg} / \mathrm{m}^{2}$, at the age of 17 years.

Genetic testing showed that he was heterozygous for A insertion at codon 112 in Melanocortin 4 Receptor.

\section{Preoperative assessment}

Hyperphagia, early weight gain, increased linear growth. Height $170.5 \mathrm{~cm}$, weight $177 \mathrm{~kg}$, body mass index 60.9 $\mathrm{kg} / \mathrm{m}^{2}$, at the age of 17 years.

Genetic testing showed that he was heterozygous for A insertion at codon 112 in Melanocortin 4 Receptor.

\section{Roux-en-Y gastric bypass (RYGB)}

It induces gastric restriction, malaborption and neurohormonal changes.

Postoperative weight loss is rapid and continues for $12-18$ months.

Average weight loss is $66-77 \%$ of excess weight.

\section{Postoperative outcome}

Achieved weight loss of $60 \mathrm{~kg}$ in the first postoperative year. Sibutramine $15 \mathrm{mg}$ daily was prescribed from 2008 to 2010 to facilitate further weight reduction.

He continues to report good post-surgical appetite suppression and to-date has achieved weight reduction of $75.8 \%$ of excess weight.

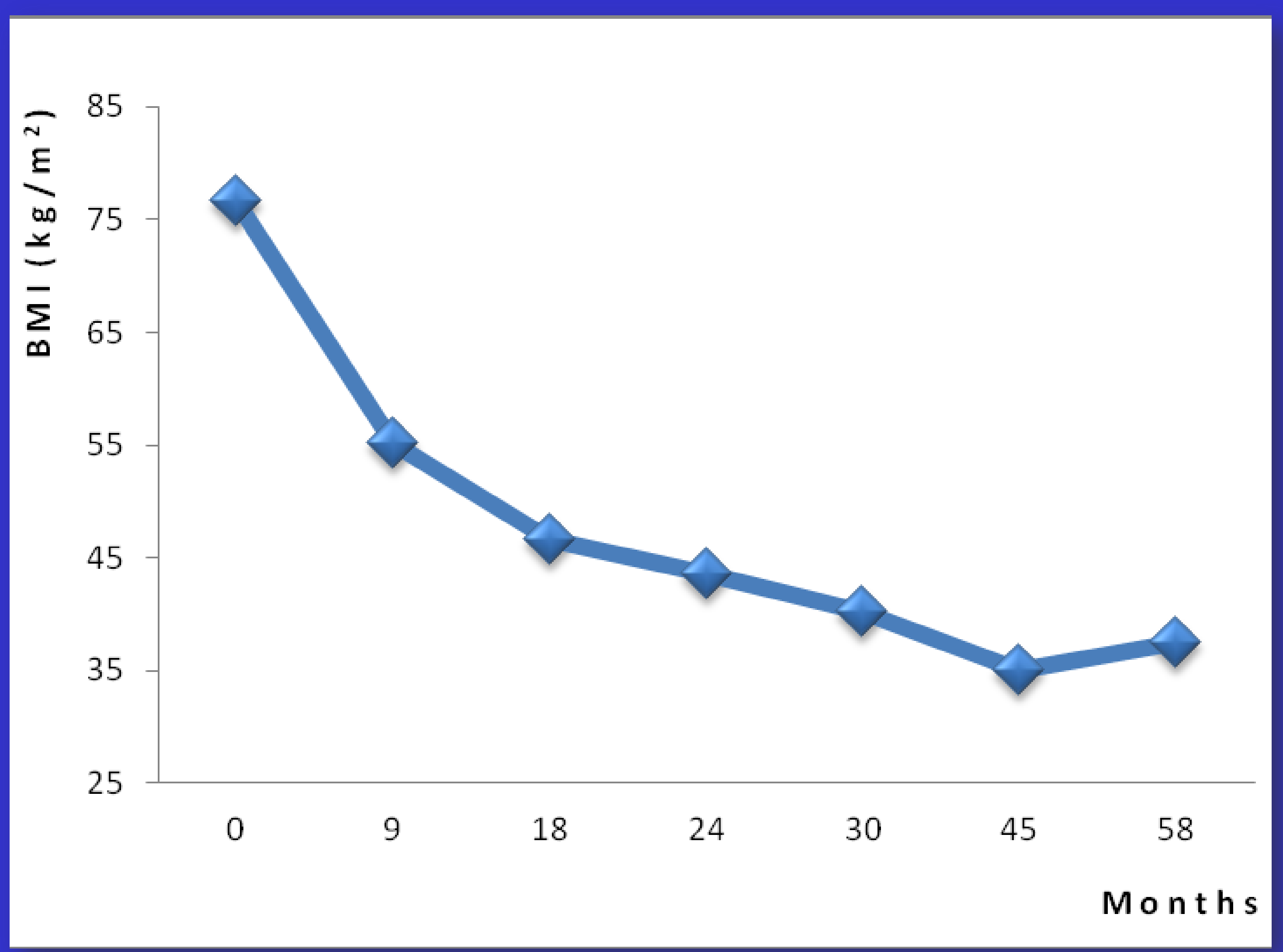

Reduction in body mass index (BMI) following gastric bypass surgery

\section{Discussion}

Heterozygous MC4R mutations have been associated with dominantly inherited obesity in various ethnic groups and nonsurgical interventions are rarely effective in the long-term. One previous report of bariatric surgery in a patient with complete MC4R deficiency reported poor weight loss after gastric banding.

We speculate that patients with MC4R mutations achieve superior weight loss outcomes from procedures such as RYGB that produce neurohormonal changes rather than gastric restriction alone. 